\title{
Coronavirus Pandemic Management in Senegal: An Interpretative Approach of Some Fighting Discursive Strategies
}

\author{
Article History \\ Received: 09.03.2021 \\ Accepted: 14.04 .2021 \\ Published: 24.04.2021 \\ Journal homepage: \\ https://www.easpublisher.com

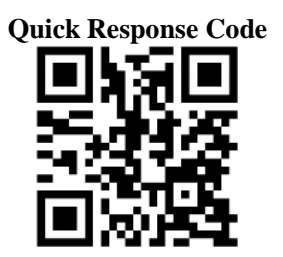

Mame Sémou Ndiaye ${ }^{1 *}$, Daouda Ngom $^{1}$ ${ }^{\mathrm{T}}$ Cheikh Anta Diop University of Dakar, Senegal

Abstract: During a crisis situation, communication by public authorities is inescapable and essential for an effective and efficient response to a situation that may endanger and jeopardize at the time life and property. Communication participates largely in the management of any crisis such as the coronavirus pandemic. Since its outbreak in Wuham (China), it has quickly spread nearly all over the world. Since its appearance on $2^{\text {nd }}$ March 2020 on Senegalese territory, the entire nation has been immersed in resolving this health crisis pandemic. All useful means such as communication are highlighted to cut the chain of contagion of the virus. In this communication against the coronavirus pandemic, we noted the presence of concepts, slogans and / or "sloganized" expressions whose understanding of their communicative values requires an operation of interpretation and decoding. The perception of the informative content of such speech acts is based on their context of use by the users. This article tries, from an interpretative analysis, to highlight some speech acts and discursive strategies created and used in the management of the pandemic, then to identify their new particularities, and to decipher their preventive content implicit in the communication of the fight against coronavirus.

Keywords: Management, health crisis, coronavirus, COVID-19, pandemic, discourse strategies.

Copyright ( $) 2021$ The Author(s): This is an open-access article distributed under the terms of the Creative Commons Attribution 4.0 International License (CC BY-NC 4.0) which permits unrestricted use, distribution, and reproduction in any medium for non-commercial use provided the original author and source are credited.

\section{INTRODUCTION}

The outbreak of a crisis situation related to a pandemic or natural disaster imposes governments and authorities to make new decisions which are appropriate to the situation. These decision-makings should be done through a good communication. That is what Paul Quinn explains in these words "communication is a critical part of any organized response to a crisis situation, whether the crisis be a natural disaster, an epidemic or a major terrorist attack" [1].

This has been the case with the coronavirus pandemic management. Since December 2019, the universe as a whole has been hit hard on all levels by one of the pandemics never known to everyone: COVID-19. The outbreak of the coronavirus disease in Wuham in China finally circumscribed the entire world, creating upheaval and forced mutations in all areas of human activity. The world is thus called upon to face an adversary as swift as it is unstoppable in terms of propagation. It is the alert in all countries, from the great powers to the underdeveloped countries to those in the process of development. Each country barricades itself, manages its communication to find a way out.
Conflicting communications arise bringing about diplomatic misunderstandings, the origin of which is the COVID 19 health crisis. We remember the communication war, through the media, between the President of the United States of America and his Chinese counterpart on the issue of the paternity of the virus with the laconic expression of Donald Trump "the chinese virus". This expression, which ends up taking on the appearance of a slogan, is amplified by the national and international media on the presentation of the pandemic, is to accuse China of owning the virus. It insinuates, moreover, the responsibility and the negligence of the Chinese authorities on the management of the spread of the virus in the world.

With the exponential speed of the pandemic's spread, speeches to the nation, accompanied by slogans, by various presidents are intensifying. The "nous sommes en guerre" (we are at war) declared by the President of France, Emmanuel Macron, is a fine illustration of the commitment and determination of the political authorities in the management of the crisis. This slogan calls the French people to understand the dangerousness of the virus and the gravity of the situation. 
In Senegal, President Macky Sall follows in the footsteps of his French counterpart by taking up the slogan in his first speech to the nation on the issue of the current health crisis by granting the same communicative content: measuring the extent of the seriousness of the situation caused by the virus. We are witnessing here an operation of warning, of prevention on the part of communicating subjects through the use of this slogan. They inform their respective countries, in other words, they communicate with their fellow citizens on the matter. To communicate is to exchange information, messages, etc. These messages are specific in terms of the concept and assessment of health risk. Communication must, in this case, be truthful and useful for citizens: "it must be continuous, transparent, independent, credible and usable by the citizen" [2].

This is to say that communication in times of crisis must be well studied and programmed in relation to the challenges of the situation: "any strategy aimed at communication planning must take into account the rules inherent in a health crisis." This state of affairs clearly proves how crucial communication is in the management of any crisis; this is what Thierry Libaert specifies in these terms: "The crisis is multifaceted. It concerns technological, social, regulatory, financial, commercial or ecological fields, but is first understood from the angle of communication. It appears omnipresent and the media, whether traditional or online, build the event as much as they amplify it. At the heart of the crisis management system, communication is the determining element which makes it possible, according to its more or less good control, to overcome the crisis [3].

In the current health crisis, we have noticed that certain "sloganized" expressions are part of the logic of respecting the rules inherent in the pandemic. Statements like "stay home! the corona is outside"," wash your hands for every thirty minutes ", wear a mask ", etc. come within the framework of the presentation of the nature of the disease (contagious, transmissible ...), and describe the forms of control means that are imposed on everyone. Such slogans, in injunctive mode, mark the beginning of the hypotheses evoked on the channels through which the virus is spread. This is the first phase of the pandemic; therefore communication focuses on the characteristics, description and routes of spread of the pandemic. Some slogans like "Be careful! COVID 19 is still there" imply a certain slowdown in the crisis. They report a certain control over the management of the health crisis. Others such as "Protect yourself to protect us!" », announce a new augmentative trend in the pandemic. Those of the type, "together to defeat COVID 19" call for citizen mobilization around the issue. Other statements like "Wear a mask, corona kills!" » warn or quite simply alert on the harmful consequences of the disease while engaging the responsibility of each citizen. We analyze in this article these communicative values, from an interpretative point of view, which arise from the use of slogans in the communication on the fight against the COVID 19 pandemic. The examples of slogans cited above demonstrate enough the situation, critical sanitary conditions in which several countries of the world such as Senegal are plunged in. Slogans whose implicit communicative values can only be deciphered by considering the current context and the evolving phase of the crisis in which they are used.

We will try in this analysis not only to indulge, beyond the typological aspect of slogans, to an exercise of pragmatic and semantic interpretation but also to an enunciative analysis in order to decipher the communicative value of these slogans. This interpretative gymnastics and this enunciative approach, combined, will allow us to bring out the denotative meaning of these lexical units, that is to say the new semantic and communicational attributes (the new meanings) that they contain. The analysis must highlight the pragmatic (and semantic) value and the discursive aim of such expressions in terms of persuasion, awareness, awareness. And the enunciative analysis of the elements of language that constitute the slogans will lead to a better understanding of said slogans.

These combined approaches will allow us to engage not only in a thematic and enunciative study of slogans but also in a pragmatic interpretation to determine the communicative function and the pragmatic value of the speech acts analyzed in the context of communication. According to Michel Hupet [4], this approach based on what is called "sentence meaning", which semantics deals with, and "utterance meaning" which concerns pragmatics., will allow starting from the first meaning to the contextual meaning of the concepts and statements deciphered in this work. The "interpretative calculations" of these branches of linguistics will also make it possible to bring out the implicitation (the implication and the presupposition) that these speech acts contain, in other words, the effects of illocutionary acts (the intention of the speaker) and perlocutionary (psychological effects) of these statements in the target.

\section{Methodological Approach}

Crisis communication has always been a fascinating research subject and experts and specialists in health crisis communication have explored a large part of such a communication constituents. The slogan as a speech act has drawn, for a long time the attention of researchers and specialists in health, political and trade union communication, in short on all forms of communication. Defined as "a concise and striking phrase used in advertising, political propaganda" », the 
slogan, by its occult and striking force, plays a multitude of discursive functions. From attention to the persuasion of the listener, the audience, the interlocutor or the receiver, these simple expressions (easy to repeat and memorize) constitute a decisive recourse in the communicative exercise of the communicating subject. Their specificity linked to their simple style means that their use in socio-political, professional, institutional, union communication, among others, fascinates experts in discourse analysis and communication.

Research on communication in general has been booming since the end of the sixties, with the meteoric growth of language and communication sciences, marked by trends such as the ethnography of communication, the ethnomethodology of communication, communicational pragmatics, and discourse analysis, among others. Specialists such as linguists and discourse analysts, sociolinguists, have made it their field of predilection for deciphering the constitutive elements of communication. Communication in socio-political fields or in times of crisis has interested researchers because of their issues and other particularities relating to the communication circumstances of the various actors. The stakes are enormous and their particularities are based on the conflicting discourses of the protagonists and this in many sectors of activity. On the political level, Patrick Charaudeau specifies that "political speeches collide a truth of appearances staged by the speech and a truth of actions implemented by decisions" [5]. Daouda Ngom adds that "the main purpose of this communication is to make oneself understood, to persuade public opinion" [6]. In times of war or health crisis, communication is the centerpiece in the process of conflict resolution or the fight against pandemics. In such situations, political positions and decision-making are required at all levels of the community, from the top of the state to the family unit. The experience of the crises experienced shows that communication remains a crucial link in the management of such crises. It is a significant thing in health situations like coronavirus pandemic. This is what Kohen Jamal Eddine and Cie explain about this pandemic in these terms:

"It constitutes an unprecedented public health crisis requiring appropriate management of citizens' information, which is an ethical and democratic requirement on the one hand, and a condition for effective management of health crises" (2020, p 2).

In managing a health crisis, all communication planning strategies take shape according to the standards relating to a health crisis. Resorting to the discursive means that language offers us becomes inevitable. Those involved in the management of the pandemic are drawing from their deepest repertoire to find the words, terms and expressions that can effectively participate in raising awareness for the fight against the spread of COVID-19. The use of slogans and attractive expressions seems appropriate for this purpose. Slogans are featured everywhere and of various kinds: "Nous sommes en guerre" (We are at war") by French President Emmanuel Macron, taken up by many of his African counterparts in their speeches to the nation during the pandemic is revealing.

The discursive strategies in the fight against COVID 19 are speech acts with an informative and preventive function. For its formal interpretative analysis, we will adopt the analysis model proposed by the telecommunications specialist, C. F Shannon, a pioneer of communication theory. A model built from five parameters present in a communication exercise: the sender of the message (politicians, trade unionist, learner), the receiver (the recipient, here, State, population), the channel (the means to transmit the message: here the voice or the written word), the message (the informational content, it is a question here of diversion of meaning, of lexical creation), the code (here the French and Wolof language). The identification of the lexical creation, in other words, what means the newly created utterance, and the discovery of the enunciative meaning, that is to say, what means the one who produces the utterance will be the stages of the process of interpretation that we intend to make for the discursive strategies and slogans of our corpus.

We cannot help espousing the pragmatic approach on the speech act in a social context to bring out the implicit aspect of the expressions analyzed in the work. Pragmatics connects speech acts to the communicative intention of the communicating subject. Here, speech acts encompass the entirety of discursive production. For Momar Cissé, the conception of this theory "cancels out the representation of communicative exchange in the form of an encoding / decoding equipollence system. Indeed, it situates discursive practice in the movement of subjectivity of which it takes charge of the different manifestations. The implications of such an approach on the design of communication are obvious» [7].

This is not about doing an analysis of these impacts; we are only trying to show the intention of the communicating subject through the lexical creation of these slogans and to highlight the semantic components and the various phenomena of subjectivity depending on the spatio-temporal updating of uttered slogans.

The problem of the use of slogans as methods of combating the spread of epidemics such as COVID 19 and above all as discursive awareness-raising strategies in the socio-political management of such pandemics has not been taken into account by previous work, at least in Senegal. The article by Momar Cissé, 
cited above, interprets the meaning of the political slogan in its relation to the conditions of production and the thought system of the author but also of the recipient public. In his article, there is no question of interpreting the contribution and the communicative value, and the lexical creation of the slogan, as we propose here. However, it contributes to the general understanding of the phenomena of subjectivity and the development of the hypotheses of the meaning of the slogan. However, we believe that studies should now be directed towards other as yet unexplored aspects of communication in times of health crisis in Senegal. Such an orientation would very well intersect with new trends in linguistics such as the analysis of health crisis communication political or union discourse, communicational pragmatics, among others.

This work, which focuses on the added value, reinforcement or impact of slogans in socio-political communication in a current situation of health crisis, poses the problem of the interpretation of the saying in situations of natural crises between state decisionmakers and the population. . There is also the problem of the formal analysis of slogans. The linguistic subtlety (change, shift in meaning, lexical substitutions, etc.) noted in the speech of these actors is part of a logic of persuasion, awareness, prevention and could pose a problem of spontaneous understanding of a third person. The article identifies and analyzes all these aspects of crisis communication in the Senegalese context from an interpretative perspective. However, the pragmatic analysis, sometimes used here, will congratulate the understanding and deciphering of the implied or presupposed information and the illocutionary force which it generates. The enunciation being the action of enunciation by speech or in writing in a communication situation, the enunciative approach will be of great importance in taking into account the context of enunciation for the interpretation of the concepts and slogans studied in this text. The collection of the data exploited in the work was carried out by ourselves through commercials, trailers, banners, daily releases from the Ministry of Health and Social Action, various speeches to the nation of the President of the Republic and brands of awareness campaigns as part of the fight and resilience against the pandemic in Senegal. Some slogans are collected from televised political debates. Sometimes, in all friendship, we discuss questions about a particular concept to have much more certainty about the use and the actual meaning of "sloganized" concepts and slogans in a crisis situation.

Some of the discursive strategies like slogans and concepts collected in this work present a communicational peculiarity and others have an extremely effective power of dissuasion and warning, the deciphering of which requires knowledge of the components of the implicit discourse of the actors in such situations of communication. In this work, the typological-interpretative approach that we use for the production of slogans of deterrence, warning, among others, is based on their general circumstances of production in relation to the evolution and management of the pandemic in Senegal.

\section{Discursive strategies, as a means of combating the pandemic}

Decidedly inscribed in a perspective that is both interpretative and pragmatic, this section highlights the typology of discursive strategies and their functionalities in "coronal" communication in Senegal. It will be a question here of highlighting the particular role of some speech acts in the communication on the presentation, the characteristics, the consequences of the pandemic within the society.

\section{Use of slogans and proverbial expressions as discursive strategies in the fight \\ Framing of the situation and description of coronavirus}

Fear is a feeling just like gladness; it arises from seeing or expecting danger. The announcement of the first case tested positive for the coronavirus, on March 2, 2020, in Senegal, had caused shudders throughout the nation. Fear of imminent danger, anxiety, and anguish amplified by the media and networks eventually created total psychosis in the country. A planned mode of communication is imposed on the authorities in order to reassure the population. Unfortunately, in phase 1 of the pandemic, the injunctive slogan Stay at home has more fear than reassurance in Senegal. Its use seemed inappropriate at the start of the crisis in a country where the informal sector polarizes more than half of the workers. The communicative aim of this injunction, which consisted of alerting citizens to the dangerousness and rapidity of spreading of the virus, was spontaneously overwhelmed by the fear of all of them of losing their jobs. It was designed more constraining than consoling. It is therefore urgent to establish a bond of trust established between the supervisory authority and the population. The department of Health and Social Action is initiating a daily meeting with the press, called "point du jour" on the situation of the day in order to relay the right information and thwart the dazzling wave of "fake news" ) social networks.

The state is thus rolling out a response plan and mobilizing both financial and communication resources. Linguistic means are set in motion. Convinced that illiteracy still reaches high proportions despite the efforts made, in addition to French, the language of education and administration, the state involves all national languages to reach all targets: the entire population. This is the start of awareness campaigns on the measures decreed by Senegalese health and paramedical authorities. And that requires a 
casting to define the speaker and the information to communicate to the recipients, for example the fellow citizens. Hence the importance of a "sloganized" communicative style if one understands that in the communication on the management of such a crisis, the messages, orders and suggestions must be concise, clear, short, coherent "and well explained for a good assimilation by the populations especially those concerning the measures impacting the socioeconomic life and the freedoms ". Any kind of ambiguity should be avoided.

The style of slogans seems more appropriate, given their accessible language simplicity and accessible to all. They are easy to memorize, repeat and learn. The actors for awareness to fight against the spread of the virus such as the musicians (rappers and mbalaxmen) involved in the awareness caravans have understood it well. Barrier gestures, taken up in French or translated into national languages such as Wolof (vehicular language, mainly spoken in Senegal), are the subject of songs, posters and signs against a backdrop of slogans. Slogans to describe the disease and its forms of contagion are put forward. We note some as takkal sa mask! koronaa defa sew (Wear your mask, the corona is thin). This slogan refers to the invisibility of the virus and above all it suggests its possibilities to easily infect people. The Wolof statement defa sew reflects a kind of contempt that we have against the virus. The verb sew in Wolof language means to be thin, small, (physically or in behavior).

Takkal sa mask! is an order in the mode of familiarity, the speaker is addressing explicitly and directly to the citizen taken individually. This is a way of encouraging everyone to feel concerned by wearing a mask. The Wolof statement bul joxe loxo, koronaa defay wale (Do not shake hands (to the other)! Corona is contagious), plays the same role, it is informative and descriptive about the ways of transmission of the virus.

\section{Discursive strategies of associating the population to the fight}

The more the number of cases tested positive for the coronavirus increases, the more the authorities evaluate the communication process to make readjustments and changes in order to dominate the situation. The full involvement of all parts of society is essential. The discourse must now be oriented towards the inclusion of all given that "communication in the management of a health crisis requires a transparent, realistic, inclusive approach which guarantees the acceptance (passivity) and adherence of the recipients to the constraints imposed by the context / activism "(Eddine et Cie, p 11). Suddenly slogans such as And faxas koronaa (Together to eliminate corona); And xeex koronaa (Together to defeat the corona), Operation daan COVID (Operation to overcome COVID), come into force. We try to involve citizens in a direct and active way. We are reaching out to them in the fight against the virus. Such an approach expresses a kind of consideration on the part of the authorities towards the recipients: the populations. Feeling considered, the latter could better become involved fiercely and above all in a disinterested manner in the management of the crisis. Such a form of communication establishes a bond of trust between the actors, state and populations. Lack of trust could skew the assimilation of messages. Eddine et Cie raise the issue of trust in a health crisis situation "in a health risk situation, trust is a complex cognitive state characterized by a mixture of rationality, feelings, and commitment to a relationship with the communicating (the institution). »(P 13).

Such lexical units target the sensitivity of citizens in an associative and inclusive manner. They are made in the form of a prompt and a suggestion to unite for better management of the spread of the virus. In this type of name, we always notice the presence of a verb or term with associative, inclusive and cooperative value. This is the role played by the phrase in bolds in: Together to conquer COVID 19, (the slogan of the Banque de l'Habitat du Senegal). The adverb together which means one with the other, with each other, is here a call for unity in dealing with the pandemic. This implies that separating each other's efforts is not ideal in this context of a pandemic. Booloo xeex korona and And daan korona, two popular slogans that suggest pooling efforts to fight the pandemic. The verbs booloo which means in Wolof to unite, to agree or to agree in order to accomplish a task and and which translates, among other things, the fact of being together, of going together, represent an invitation to collaboration for more strength and resilience in the fight. This desire or wish to be stronger and more resilient, is justified by the use of the verbs xeex and daan in the statements Booloo xeex korona and And daan korona which mean respectively to unite to fight the corona; come together to defeat the corona. The use of the verbs xeex and daan clearly demonstrates that this is an opponent to be defeated. Here, korona (Wolof script) is the adversary to be fought, to be overcome in a surge of collective solidarity.

The composition of these verbal statements booloo xeex and and daan comprises an extraordinary strike force, and psychologically acts on the population. This kind of expressions presupposes a need to collaborate for a collective management and a mobilization of all the forces of the nation, starting from the family unit to the top of the State with a view to limiting the spread of the virus and eliminating it definitely. The use of such slogans suggests a national union around the health emergency: the pandemic. Here we are witnessing very strong lexical choices from a semantic and above all communicational point of view, which highlight the current health emergency. 
In health crisis communication, the emphasis is often on the disease, more precisely on the symptoms, transmission, means of protection, the most vulnerable people and finally on the ways out of the crisis. We want people to be cautious. This is what justifies the use of lexical units with associative value, a way of telling the population that this is a collective affair and that everyone should be involved. This communicative strategy corresponds to a reminder intended for the population to draw their attention to the gravity of the situation. The Wolof verbs booloo and and play this associative function. They oppose verbs with a dissociative or exclusive function such as xaajoo (to separate, to divide), tasaaroo (to scatter, to disunite), the use of which seems inappropriate as discursive strategies or in the formation of slogans in the fight against the pandemic.

\section{Strategies based on calls for caution and responsibility}

We mentioned above that communication strategies are put up following the progression or regression of the pandemic, in other words, of the virus. It is important to remember that the typology of communicational approaches for instance the use and formation of slogans or sloganized statements, operates according to the evolution of the pandemic, in other words, according to the decrease or increase in cases of contamination. In Senegal, President Macky Sall has addressed the nation on several occasions within the framework of the problematic and even restrictive management of the pandemic and especially to expose the populations to the economic difficulties caused by the pandemic. That occurred when the country's economy was on its knees, with job losses noted here and there, putting the Senegalese state in an unbearable financial situation. Faced with this situation of economic crisis caused by the health crisis of the pandemic, the president made an address to the nation consisting in easing the restrictive measures taken as part of the fight against the spread of the virus and released the famous sentence "We have to learn to live with the virus". It is the start of a new turn in the life of Senegalese people in times of pandemic. The assertion ended up taking on the appearance of a popular slogan, repeated or taken up by the Senegalese as evidence or justification of their actions and attitudes tending to flout barrier measures. This communication "bomb" of President Sall is the result of an unprecedented relaxation of the population compared to the caution advocated and the measures decreed by the health services of the Ministry of Health and Social Action. The segment "live with the virus" of his statement is used as evidence and justification. The use of this statement presupposes, for some, an admission of the failure of the response plan set in motion by the government to contain the spread of the virus. Speaking it out of disrespect for barrier measures is like blaming
President Sall for calling on the people to "learn to live with the virus." This is a slogan justifying the relaxation of the people regarding respect for barrier measures.

Despite this misinterpretation of President Macky Sall's message to the nation, there followed a downward trend in positive cases of the first wave of COVID 19 contamination, which also favored carelessness, neglect, relaxation of masses in relation to compliance with barrier measures: correct mask wearing, social or physical distancing, frequent hand washing, among others. But the downtrend was fleeting. A second wave of more severe contamination hits Senegal, causing psychosis, anguish, and fear. The English variant of the virus is the origin, hence the new restriction measures taken by the President of the Republic. A new communication approach is being put in place and slogans and statements serving as an alert or warning come into effect. This is the communicative strategy of calling for caution and individual and / or collective responsibility, not to say panic. Hence the entry into force of slogans that tend to personalize the fight, that is to say, everyone is called on to make their own arrangements to break the chain of contagion of the disease. Communication changes paradigm, we start from the individual to the collective.

This passage or communicational targeting is expressed by Wolof sloganized statements such as Takkal sa mask, Aar sa boppou Aar sa mbokkou (Wear your mask! Protect yourself to protect your neighbor!) of Keur Mbaye Fall 's Matal movement. The use of the injunction in the imperative of the second person singular intWolof aims to eliminate any communicational ambiguity: the recipient is "you", who represents everyone but individually. Everyone feels concerned and even considers themselves to be the main recipient of the message.

"You" that refers to everyone carries on his shoulders the responsibility of protecting his counterpart. Everyone is consideres responsible for any failure on his part that could cause contamination to his fellow citizen. Beyond his own protection, we are trying to make him more careful, more vigilant to participate in one way or another in breaking the chains of contaminations of the virus. This communication strategy is very striking and effective because it acts on the psychology of the population. Achieving the disease through lack of respect for sanitary measures to be observed or not even arouses within society a sort of stigmatization from neighbors, all the more so to infect it with its neighbor, which would be a heavy psychological responsibility to bear. The switched statement (Wolof-French) jëf ngir aar sa ma njaboot, pour vous protéger et protéger votre famille portez un

${ }^{1}$ Township in Dakar 
masque (try to protect yourself and your family, wear a mask!), launched by Orange info services is in line with everyone's responsibility. The burden of protecting the family against the virus is placed on each member of the family. Here, we play on each person's sensitivity and love for their own family. We make the struggle a family affair first before making it a matter of the community at large. Wear a mask that is the driving force behind the statement is the action expected of each individual for the good of their own family.

Ultimately, one can conceive of such statements or slogans as communication strategies that are assimilated to warnings given to the population. Warning slogans sound like panic in the form of an injunction. Implicitly, they refer to the risks or dangers of death linked to the severity of the disease. Such statements are real "dissuaders", they invite the Senegalese to be vigilant, to be cautious in this context of pandemic.

This discursive approach under the appearance of suggestion is assimilated to an alert aimed at populations in the context of the fight against the virus. This communicative process presupposes a danger that the community runs, and which depends on its expected behaviors to save themselves and others. It is a call for vigilance, caution and respect for all measures taken to stem the spread of the virus within society. The statements takkal sa mask, Aar his boppou Aar his mbokkou (Wear your mask! Protect yourself to protect your neighbor!) and jëf ngir aar sa ma njaboot, (to protect yourself and your family, wear a mask!) include valuable speech acts perlocutionary given that they deliver messages that empower without necessarily saying so. This discursive strategy with a purely persuasive aim in crisis communication consists of "making the Senegalese populations aware of the existence and the seriousness of the disease; make the Senegalese populations understand the manifestations of the disease and the barrier gestures to observe in order to prevent it; Make Senegalese populations adopt the expected behaviors to save themselves and others. ". The concepts and slogans used here for the fight against the coronavirus constitute inclusive, suggestive, sensitizing communication techniques for the targeted populations. This is to say communication is multifunctional in resolving a health crisis situation.

\section{CONCLUSION}

Through this study, we noticed that the communication of the health crisis in general of the fight against the coronavirus pandemic is intended to be transparent communication, well adapted and evaluated according to the stages of the evolution of the pandemic. Using appropriate communication means can help people in taking precaution and avoiding behaviors that may put them at risk. The discursive strategies through speech acts like slogans and concepts studied in this article explicitly or implicitly expose all the health risks run by the population. They also make people aware of the deadly consequences of the spread of the virus. This communication through poignant and striking concepts and slogans on the fight against the pandemic of the pandemic in Senegal invites the target (population) to become actively involved in strict compliance with preventive measures. Communicating persons adopt an awareness-raising process through a continuous, dynamic, inclusive and well-adjusted communication approach. Communication is an effective tool in the management of a health crisis such as the present COVID 19 pandemic. It is an essential lever in the exposure and presentation of the characteristics of the pandemic in order to better manage, reduce or destroy it, eliminate it definitely. Communication strategies used during a health crisis situation vary "at what stage the communication in question is occurring e. g pre, during or post crisis."

\section{REFERENCES}

1. Quinn, P. (2018). Crisis Communication in Public Health Emergencies: The Limits of 'Legal Control' and the Risks for Harmful Outcomes in a Digital Age in Life Sciences, Society and Policy.

2. Eddine, K. J. (2005). Crise sanitaire et stratégie de communication.

3. Libaert, T. H. (2015). Communication de crise. Quatrième édition, DUNOD.

4. Hupet, M. (1993). La pragmatique in Tendances actuelles en Linguistiques générale, Nespoulous, J. L. (1993). Paris, Delachaux et Niestlé.

5. Charaudeau, P. (2005). Le discours politique. Les masques du pouvoir. Paris: Vuibert.

6. Ngom, D. (2017). Langues nationales et communication politique au Sénégal, Essai typologique des stratégies de persuasion à travers quelques dénominations wolof données aux coalitions politiques des élections locales du 29 Juin 2014: le cas du département de Dakar, in Langues et Littératures, Revue du Groupe d'études linguistiques et littéraires, 2:45-65, UGB, Sénégal.

7. Cisse, M., \& Diakite, M. (2007). Linguistique, analyse du discours et interdisciplinarité. Université du Sénégal, 116-130.

Cite This Article: Mame Sémou Ndiaye \& Daouda Ngom (2021). Coronavirus Pandemic Management in Senegal: An Interpretative Approach of Some Fighting Discursive Strategies. EAS J Humanit Cult Stud, 3(2), 111-117. 